\title{
Anticoagulation Control in Different Ethnic Groups Receiving Vitamin K Antagonist for Stroke Prevention in Atrial Fibrillation
}

\author{
Nur Azyyati Zawawi ${ }^{1}$, Izzati Abdul Halim Zaki ${ }^{1,2}$, Long Chiau Ming ${ }^{3}$, Hui Poh Goh ${ }^{3}$ and \\ Hanis Hanum Zulkifly ${ }^{1,2 *}$
}

1 Department of Pharmacy Practice, Fakulti Farmasi, Universiti Teknologi MARA (UiTM), Bandar Puncak Alam, Malaysia, ${ }^{2}$ Cardiology Therapeutics Research Group, Universiti Teknologi MARA, Bandar Puncak Alam, Malaysia, ${ }^{3}$ Pengiran Anak Puteri Rashidah Sa'adatul Bolkiah (PAPRSB) Institute of Health Sciences, Universiti Brunei Darussalam, Gadong, Brunei

\section{OPEN ACCESS}

Edited by:

Gen-Min Lin,

Hualien Armed Forces General

Hospital, Taiwan

Reviewed by:

Chien-Yi Hsu,

Taipei Medical University

Hospital, Taiwan

James T. H. Teo,

King's College Hospital NHS

Foundation Trust, United Kingdom

*Correspondence:

Hanis Hanum Zulkifly

hanish2984@uitm.edu.my

Specialty section:

This article was submitted to Cardiovascular Epidemiology and

Prevention,

a section of the journa

Frontiers in Cardiovascular Medicine

Received: 05 July 2021 Accepted: 18 October 2021 Published: 16 November 2021

Citation: Zawawi NA, Abdul Halim Zaki I, Ming LC, Goh HP and Zulkifly HH (2021) Anticoagulation Control in Different Ethnic Groups Receiving Vitamin K Antagonist for Stroke

Prevention in Atrial Fibrillation. Front. Cardiovasc. Med. 8:736143. doi: 10.3389/fcvm.2021.736143
Vitamin $\mathrm{K}$ antagonist such as warfarin reduces the risk of stroke in atrial fibrillation (AF) patients. Since warfarin has a narrow therapeutic index, its administration needs to be regularly monitored to avoid any adverse clinical outcomes such as stroke and bleeding. The quality of anticoagulation control with warfarin therapy can be measured by using time in therapeutic range (TTR). This review focuses on the prevalence of $\mathrm{AF}$, quality of anticoagulation control (TTR) and adverse clinical outcome in AF patients within different ethnic groups receiving warfarin therapy for stroke prevention. A literature search was conducted in Embase and PubMed using keywords of "prevalence," "atrial fibrillation," "stroke prevention," "oral anticoagulants," "warfarin," "ethnicities," "race" "time in therapeutic range," "adverse clinical outcome," "stroke, bleeding." Articles published by 1st February 2020 were included. Forty-one studies were included in the final review consisting of AF prevalence ( $n=14$ studies), time in therapeutic range ( $n=18$ studies), adverse clinical outcome ( $n=9$ studies) within different ethnic groups. Findings indicate that higher prevalence of AF but better anticoagulation control among the Whites as compared to other ethnicities. Of note, non-whites had higher risk of strokes and bleeding outcomes while on warfarin therapy. Addressing disparities in prevention and healthcare resource allocation could potentially improve AF-related outcomes in minorities.

Keywords: atrial fibrillation, ethnicity, time in therapeutic range (TTR), adverse clinical outcomes, anticoagulant

\section{INTRODUCTION}

Atrial fibrillation $(\mathrm{AF})$ is an atrial tachyarrhythmia that has an uncoordinated atrial activation, with consequent atrial mechanical function deterioration (1). Based on the latest European Society of Cardiology Guidelines, AF had remained one of the world's main causes of stroke, heart failure, sudden death and cardiovascular disease (2). The prevalence of AF has been increasing throughout the world affecting 8 million people in Europe and this is expected to increase 2-3-fold by 2030 (3). Older age, male sex, diabetes, and ischemic heart disease are factors associated with AF diagnosis (4). The use of Vitamin K antagonist (VKA) in AF patients is associated with a reduction in the risk of thromboembolic complications when time in therapeutic range (TTR) $>70 \%$ is achieved (5). TTR is the time spent within the therapeutic range of INR (2.0-3.0) (6). Patients with TTR $\geq$ 
$70 \%$ are considered to have a well-controlled warfarin therapy while those with TTR $\leq 70 \%$ are considered as poorly controlled warfarin therapy (6). Current research suggests that high TTR in patients treated with warfarin for AF correlates with better patient outcomes (6). However, challenges arise in identifying patients who are likely to achieve and maintain therapeutic INR as well as good anticoagulation control. The quality of anticoagulation control can be influenced by many factors. Ethnicity has been established as one of the factors that might impact anticoagulation control (7). A clinical scoring system, the SAMe-TT $\mathrm{R}_{2}$ score was developed in 2013 that presents the most common clinical and demographic factors that might influence anticoagulation control in AF patients (7) and nonwhite ethnicity is included in this scoring system. The score can be used to aid decision making by identifying those patients who would probably do well when treated with VKA (achieving a high TTR, $>65 \%$ ) or, conversely, those who would need additional interventions to achieve good INR control or

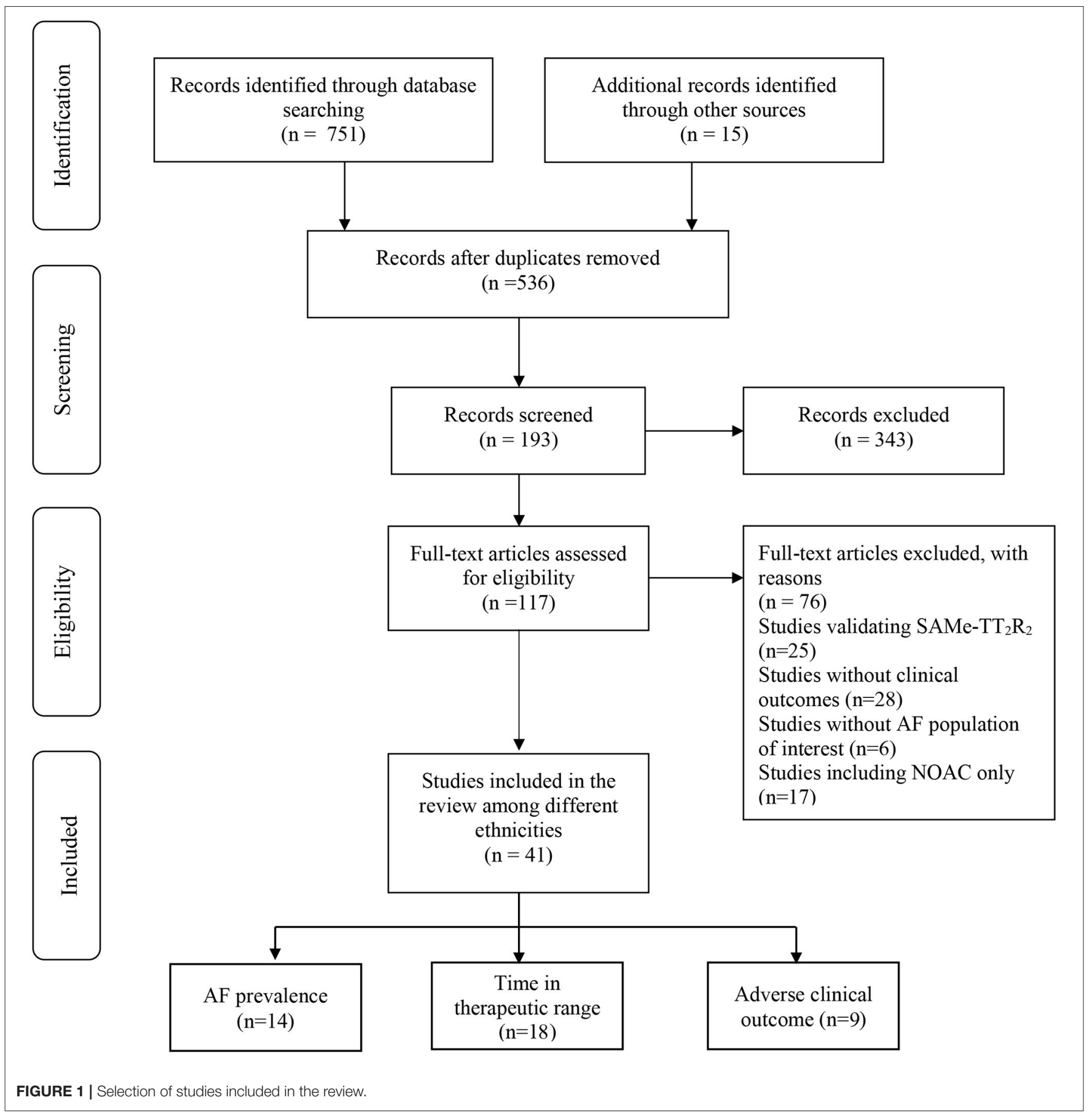


to be initiated on/switched to a non-VKA oral anticoagulant (NOAC) (7).

Stroke is a long-term complication related to AF when effective measures of stroke prevention is not taken (2). Stroke tends to be more severe with a higher recurrence in AF patients reaching $6.9 \%$ compared to $4.7 \%$ in patients with stroke without atrial fibrillation (2). The $\mathrm{CHA}_{2} \mathrm{DS}_{2}$-VASc score, a well-validated score has been used worldwide to identify AF patients' risk factors of stroke and the need for oral anticoagulation therapy. Patients with a low risk factor of stroke from the $\mathrm{CHA}_{2} \mathrm{DS}_{2}$ VASc $\left(\mathrm{CHA}_{2} \mathrm{DS}_{2}\right.$-VASc 0 in male and 1 in female) do not require antithrombotic treatment, while patients with risk factors for strokes (i.e., $\mathrm{CHA}_{2} \mathrm{DS}_{2}$-VASc of 1 or more for males and 2 or more for females) require oral anticoagulation therapy to prevent the risk of stroke (2). Vitamin $\mathrm{K}$ antagonist (e.g., warfarin) is one of the effective oral anticoagulants (OAC) that can be used to reduce the risk of stroke from AF by $64 \%$ (8). Nonetheless, bleeding risk is a major concern for AF patients taking warfarin therapy. Uncontrolled monitoring of warfarin therapy is associated with major bleeding in AF patients (9, 10). The risk of bleeding can be measured by using the HASBLED scoring system where a risk of bleeding $\geq 3$ indicates high-risk bleeding and a score of $<3$ indicates low risk of bleeding (2).

The prevalence of AF, quality of anticoagulation and adverse clinical outcome among different ethnic groups varies and was seen to be poor among non-white ethnicities. Hence, this is the first review that reports on the prevalence of $\mathrm{AF}$, the quality of anticoagulation control (TTR) and adverse clinical outcome among different ethnic groups receiving warfarin therapy for stroke prevention.

\section{METHOD}

A literature search was conducted on Embase and PubMed using keywords of "prevalence," "atrial fibrillation," "stroke prevention," "oral anticoagulants," "warfarin," "ethnicities," "race" "time in therapeutic range," "adverse clinical outcome," "stroke, bleeding." Articles published by 1st February 2020 were included. Given the lack of large scale RCTs in this population, evidence from prospective and retrospective studies were incorporated. Besides, they serve as "real-world" evidence on oral anticoagulant (OAC) use in AF patients with different ethnicities. Forty-one studies were included in the final review consisting of AF prevalence ( $n$ $=14$ studies), time in therapeutic range ( $n=18$ studies), adverse clinical outcome ( $n=9$ studies) within different ethnic groups (Figure 1).

\section{AF AMONG DIFFERENT ETHNIC GROUPS}

The prevalence of AF differs between each ethnics group. Table 1 represents 14 studies (11-24) on the prevalence of AF based on different ethnic groups. According to all studies, White people have the highest prevalence of AF compared to Afro-Caribbean, Asian, Hispanic and others ranging from $1.2 \%$ (12) to $29 \%$ (19).
Only 3 studies $(11,22,24)$ investigated AF diagnosis within the Hispanics ranging from 2.6 to $7.8 \%$. While eight other studies $(11-13,15,18,20,22,24)$ reported on AF prevalence within Asians ranging from 0.05 to $10.1 \%$. There was only one study (24) reported prevalence of AF among Native American (4.4\%) and Pacific Islandar/Hawaiian (4.6\%) and another study (15) which reported the prevalence of AF in Malaysia according to its ethnic groups with Malay $(0.77 \%)$, Chinese $(0.05 \%)$, others $(0.06 \%)$. Besides, a study by Shavadia et al. (25) also reported that Asian ethnicity has been associated with considerably lower AF rates compared to White ethnicity. Differences in clinically detected AF among different ethnic group might be evident. It could reflect the variations in clinical recognition of AF, perception of AF symptoms or access to health care, the limited participation of minorities in trials and clinical studies for AF; or also due to difference in the completeness of clinical assessment when patients are presented with AF symptoms (11).

\section{TIME IN THERAPEUTIC RANGE AMONG WARFARIN USERS WITHIN DIFFERENT ETHNIC GROUPS}

Time within the therapeutic range (TTR) is used to evaluate anticoagulation control in patients on warfarin therapy for stroke prevention in AF. TTR has a significant impact on patient outcomes such as stroke and mortality $(6,26)$. As shown in Table 2, most of the studies used TTR $\geq 70$ as their cut-off point indicating good anticoagulant control in AF patients. Moreover, there were also other studies $(30,32)$ that used TTR $\geq 60$ and TTR $\geq 65$ as their cut-off point to indicate good anticoagulant control among their AF patients.

Among the 18 studies $(9,26-42)$ from the findings, eight studies $(27,28,32,33,37-39,42)$ stated TTR among each specific ethnic groups in their population and the other 10 studies $(9,29-31,34-37,40,41)$ only mentioned the TTR in their overall population (whites, Asians). So far, in Malaysia, there is no study being conducted that focused on TTR among different ethnic groups. However, a study by Yap et al. (35) at Malaysia's National Heart Institute reported only $53.2 \%$ of their overall patients had a TTR $\geq 70$. Furthermore, in one Singaporean study (33), Chinese patients were reported to have higher mean TTR than Malays with 58.7 and 55.2\%, respectively. One study in China (36) showed the percentage of people with TTR $\geq 70$ was only $10.7 \%$ while TTR $\leq 70 \%$ was $89.3 \%$ which indicated poor anticoagulation control of warfarin therapy in both countries. Interestingly, Nguyen et al. (28) also reported lower TTR among their 512 Indigenous vs. nonindigenous Australian patients with AF [40 (29) vs. 50 (31); $p=0.006]$. Based on the previous study by Golwala et al. (37) black individuals had lower median TTRs (59\%) than Hispanic (62\%) and white (68\%) participants; consistent with findings from the sub study of IMPACT trial (38). In relation to a previous study by Zulkifly et al. (27) the researchers also found that the quality of anticoagulant control differs based on ethnicity whereby South Asians and Afro-Caribbeans had poor 
TABLE 1 | Prevalence of AF by ethnicity.

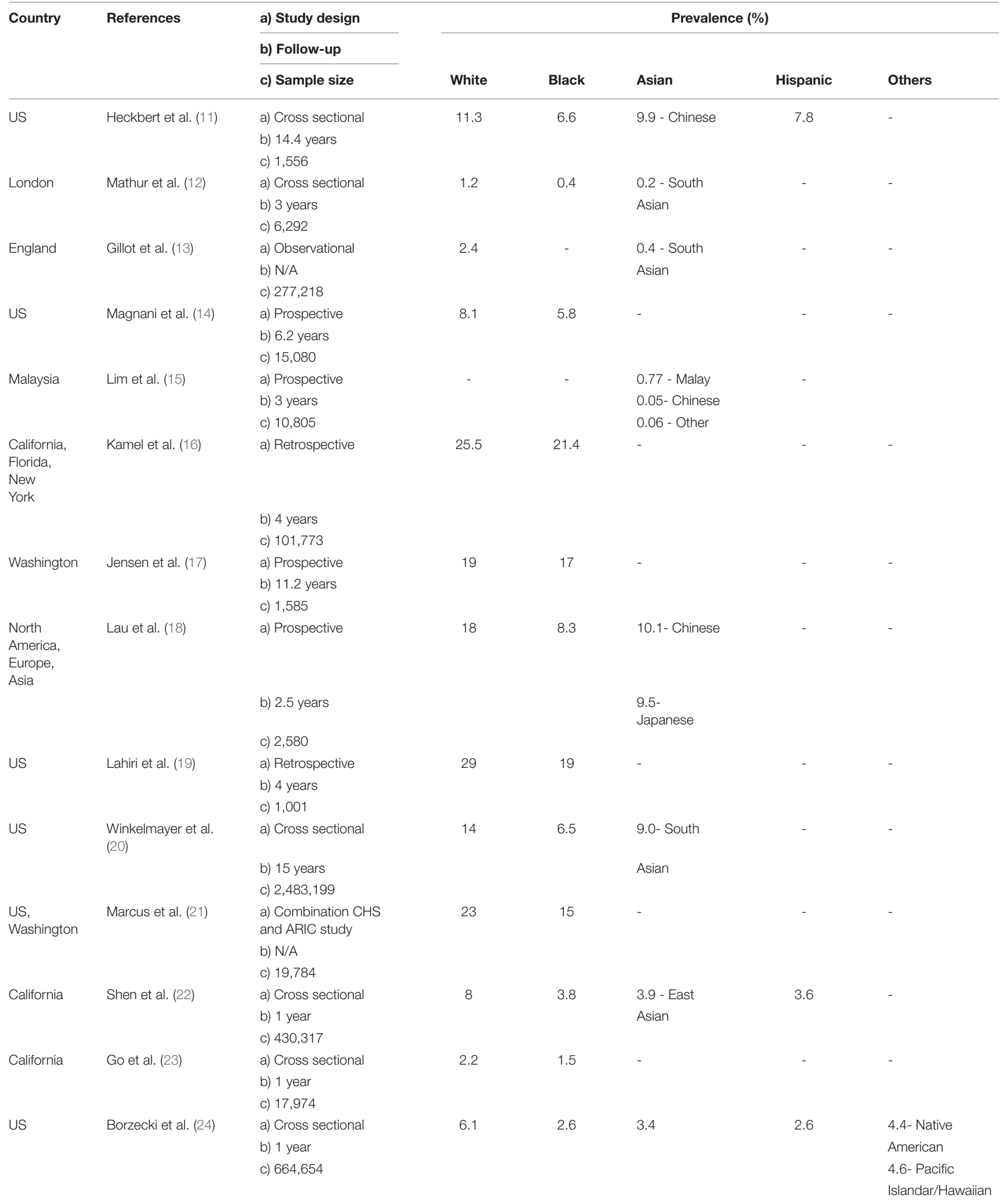


TABLE 2 | Mean TTR of patients among different ethnic group.

\begin{tabular}{|c|c|c|c|c|c|c|c|}
\hline \multirow[t]{2}{*}{ Country } & \multirow[t]{2}{*}{ References } & \multirow{2}{*}{$\begin{array}{l}\text { a. } \\
\text { b. }\end{array}$} & \multirow{2}{*}{$\begin{array}{l}\text { Study design } \\
\text { length of follow up }\end{array}$} & \multirow{2}{*}{$\begin{array}{l}\text { a. } \\
\text { b. }\end{array}$} & \multirow{2}{*}{$\begin{array}{l}\text { Sample size } \\
\text { race/ethnicity }\end{array}$} & \multirow[t]{2}{*}{$\begin{array}{l}\text { Method INR } \\
\text { monitoring }\end{array}$} & \multirow[t]{2}{*}{ Mean TTR } \\
\hline & & & & & & & \\
\hline \multirow[t]{3}{*}{ United Kingdom } & Zulkifly et al. (27) & a. & Retrospective & a. & 1,070 & Anticoagulant & White $=67.9$ \\
\hline & & b. & 11 months & b. & $\begin{array}{l}\text { Whites, Afro } \\
\text { Caribbean, South Asian }\end{array}$ & clinic & Afro- Caribbean $=61.3$ \\
\hline & & & & & & & South Asian $=60.5$ \\
\hline \multirow[t]{2}{*}{ Australia } & Nguyen et al. (28) & a. & Retrospective & a. & 512 & Hospital based & Indigenous = 40 (29) \\
\hline & & b. & $\mathrm{n} / \mathrm{a}$ & b. & $\begin{array}{l}\text { Indigenous, } \\
\text { non-Indigenous }\end{array}$ & & $\begin{array}{l}\text { non-Indigenous }=50 \\
(31)\end{array}$ \\
\hline \multirow[t]{2}{*}{ China } & Li et al. (29) & a. & Prospective & a. & 379 & Hospital based & Overall mean \\
\hline & & b. & 3 months & b. & Chinese & & TTR 58.35 (26.3) \\
\hline \multirow[t]{2}{*}{ Lithuania } & Urbonas et al. (30) & a. & Retrospective & a. & 406 & $\begin{array}{l}\text { Primary health } \\
\text { care centre }\end{array}$ & $T \mathrm{TR}>65=20.4$ \\
\hline & & b. & 12 months & b. & - & & $\mathrm{TTR}<65=79.6$ \\
\hline \multirow[t]{2}{*}{ Spain } & $\begin{array}{l}\text { Roldán Rabadán } \\
\text { et al. (31) }\end{array}$ & a. & Prospective & a. & 1,584 & Hospital based & $\Pi \pi R>70=40$ \\
\hline & & b. & 3 years & b. & Whites & & $\pi \mathrm{TR}<70=60$ \\
\hline \multirow[t]{2}{*}{ Australia } & Bernaitis et al. (9) & a. & Retrospective & a. & 3,199 & Hospital based & $T \mathrm{TR}>70=82$ \\
\hline & & b. & 6 months & b. & Whites & & $\Pi \mathrm{TR}<70=20$ \\
\hline \multirow[t]{5}{*}{ Qatar } & $\begin{array}{l}\text { Mohammed et al. } \\
\text { (32) }\end{array}$ & a. & Retrospective & a. & 241 & $\begin{array}{l}\text { Anticoagulant } \\
\text { clinic }\end{array}$ & $\pi \mathrm{TR}>65=65.1$ \\
\hline & & b. & $>6$ months & b. & Asian & & $T \mathrm{TR}<65=34.9$ \\
\hline & & & & & & & Mean TTR: \\
\hline & & & & & & & Arab = 71 \\
\hline & & & & & & & Asian= 67 \\
\hline \multirow[t]{4}{*}{ Singapore } & Bernaitis et al. (33) & a. & Retrospective & a. & 1,137 & Hospital based & Mean TTR: \\
\hline & & b. & 6 months & b. & Malay & & Malay $=55.2$ \\
\hline & & & & & Chinese & & Chinese $=58.7$ \\
\hline & & & & & Indian & & Indian = 49.7 \\
\hline \multirow[t]{2}{*}{ Iran } & $\begin{array}{l}\text { Abbasinazari et al. } \\
\text { (34) }\end{array}$ & a. & Cross sectional & a. & 470 & $\begin{array}{l}\text { Anticoagulant } \\
\text { clinic }\end{array}$ & $\pi R>70=37.3$ \\
\hline & & b. & 6 months & & & & $\mathrm{TTR}<70=62.7$ \\
\hline \multirow[t]{2}{*}{ Malaysia } & Yap et al. (35) & a. & Retrospective & a. & 500 & Hospital based & $\mathrm{TTR}>70=53.2$ \\
\hline & & b. & $>12$ months & b. & Asian & & $\mathrm{TTR}<70=46.8$ \\
\hline \multirow[t]{2}{*}{ China } & Chan et al. (36) & a. & Retrospective & a. & 1,428 & Hospital based & $T \mathrm{TR}>70=10.7$ \\
\hline & & b. & 14 years & b. & Chinese & & $\pi \mathrm{TR}<70=89.3$ \\
\hline \multirow[t]{4}{*}{ California } & Golwala et al. (37) & a. & Prospective & a. & 9,542 & Outpatient & Mean TTR: \\
\hline & & b. & 15 months & b. & White & & White $=68$ \\
\hline & & & & & Black & & Black = 59 \\
\hline & & & & & Hispanic & & Hispanic $=62$ \\
\hline $\begin{array}{l}\text { North } \\
\text { America, } \\
\text { Europe, } \\
\text { Australia }\end{array}$ & Lip et al. (38) & $\begin{array}{l}\text { a. } \\
\text { b. }\end{array}$ & $\begin{array}{l}\text { Randomised controlled } \\
\text { trial }(\mathrm{RCT}) \\
2 \text { years }\end{array}$ & $\begin{array}{l}\text { a. } \\
\text { b. }\end{array}$ & $\begin{array}{l}2,718 \\
\text { White, Black, Asian, } \\
\text { Non-Hispanic, Hispanic }\end{array}$ & $\mathrm{RCT}$ & $\begin{array}{l}\text { Mean TTR: } \\
\text { White; } 55.2 \\
\text { Black: } 44.0 \\
\text { Asian: } 67.0 \\
\text { Non-Hispanic: } 53.7 \\
\text { Hispanic: } 47.8\end{array}$ \\
\hline \multirow[t]{3}{*}{ US } & Yong et al. (39) & a. & Retrospective & a. & 184,161 & Outpatient setting & Mean TTR \\
\hline & & b. & 1 year & b. & Blacks, whites & & White: 57\% \\
\hline & & & & & & & Black: 49\%; $p<0.001$ \\
\hline
\end{tabular}


TABLE 2 | Continued

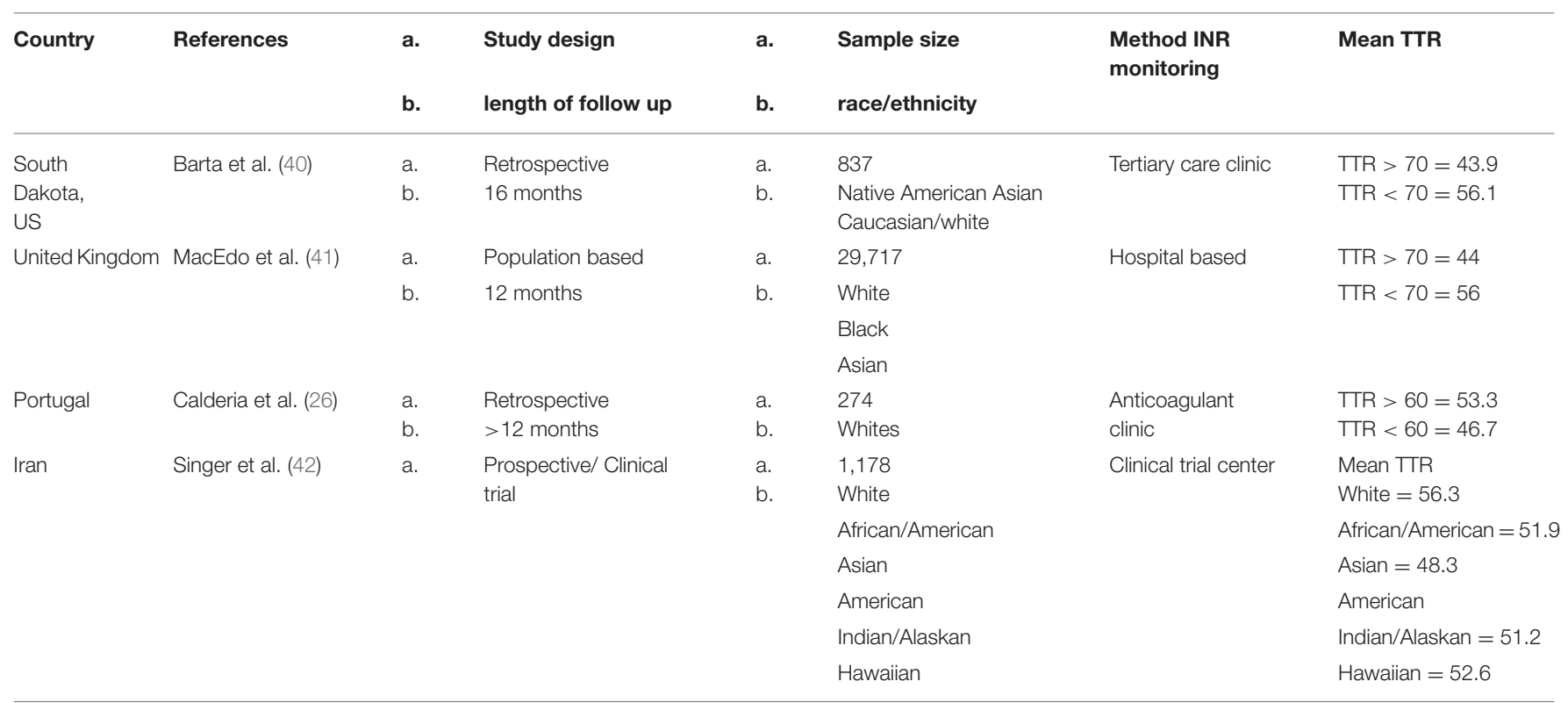

anticoagulant control with their mean TTR of 60.5 and $61.3 \%$, respectively as opposed to White people with $67.9 \%$ (27). Hence, these studies indicate that white people have better anticoagulant control compared to other ethnic groups. Birman-Deych et al. (43) claimed that warfarin did not offer advantages in blacks and Hispanics, partially due to less effective warfarin care and anticoagulation monitoring.

These observations may be due to various reasons, for example differences comorbid disease, socioeconomic status, poor understanding of therapy, adherence issue and genetic background. Ethnic differences in anticoagulation control were evident in a cohort of 9,542 patients (37) receiving warfarin therapy for various indications (AF, VTE, and other mixed conditions), with lower mean TTR among the Blacks compared to Whites. Blacks were younger and lived in areas of highest quartile of poverty, had higher illness burden including more comorbid disease, requiring more medications and hospitalisations to manage those conditions compared to White patients (37). After accounting for all these factors, which are mostly non-modifiable, Black patients still had a recorded TTR 2.3\% lower than White patients (37). Meanwhile, poor TTR among Asians might be affected by their dietary intake and extensive use of herbal medications (44). Furthermore, it is not common to have a structured anticoagulant clinic in many parts of the Asian countries causing more challenges in optimising INR control (44).

In terms of pharmacogenetics, warfarin metabolism and dose requirements might differ between ethnic groups. Studies have shown that warfarin dosage requirements are higher in Blacks compared to Whites partly due to racial differences in genotype frequencies (45). Blacks have been found to have additional CYP2C9 alleles which are associated with reduced function of the CYP2C9 activity and thus might contribute to dose variability (45). In addition, issues like variability of health literacy, adherence to medication might also contribute to the differences in quality of anticoagulation therapy among different ethnic groups (37). Perhaps these issues could "flag" the physicians to have a closer and more frequent follow up among ethnic minority patients who are having difficulties in achieving therapeutic INR with warfarin therapy. Otherwise, if without budget constraint, NOACs are in preference to Vitamin $\mathrm{K}$ antagonist (VKA) in these patients based on the latest ESC guideline on management of $\mathrm{AF}$ (evidence grade 1C) (2).

\section{ADVERSE CLINICAL OUTCOME AMONG AF PATIENTS WITHIN DIFFERENT ETHNIC GROUPS}

Warfarin, apart from having a narrow therapeutic index which requires frequent INR monitoring, multiple major drug-drug interaction and drug-food interaction have been documented. Its usage is also associated with adverse event such as thromboembolic and bleeding complications if the quality of anticoagulation control is not optimized. According to Pastori et al. (4) good TTR $(>70 \%)$ is associated with a low risk of stroke and bleeding. Table 3 outlines adverse clinical outcomes among different ethnic groups based on 9 studies (10, 27, 36, $38,46-50)$. Five studies $(27,36,46-48)$ focused on the adverse clinical outcomes in each ethnic group while the other four studies $(10,38,49,50)$ focused on the overall population. Referring to study Shen et al. (47). African American or black people has a high risk of stroke compared to other ethnic groups. Similarly, Zulkifly et al. (27) reported that black people had the highest proportion of stroke and bleeding complications (9.8 and 6.5\%) compared to White (4.5 and 
TABLE 3 | Percentage of adverse clinical outcome by ethnicity.

\begin{tabular}{|c|c|c|c|c|c|c|c|}
\hline \multirow[b]{2}{*}{ References } & \multicolumn{7}{|c|}{ Adverse outcome (\%) } \\
\hline & Adverse outcome & White & Black & Asian & Hispanic & Others & $\begin{array}{c}\text { Overall } \\
\text { population }\end{array}$ \\
\hline \multirow[t]{2}{*}{ Kabra et. al (46) } & Stroke & 23 & $\begin{array}{l}38 \text { - African } \\
\text { American }\end{array}$ & - & 27.8 & $\begin{array}{l}28.7 \text { - Native } \\
\text { American }\end{array}$ & - \\
\hline & & & & & & $\begin{array}{l}\text { 22.8- Pacific } \\
\text { islander }\end{array}$ & \\
\hline Shen et. al (47) & $\mathrm{ICH}$ & 0.34 & 0.77 & 1.75 & 0.73 & - & - \\
\hline Chan et. al (36) & IS & - & - & $\begin{array}{l}23.7- \\
\text { Chinese }\end{array}$ & - & - & - \\
\hline Wang et. al (48) & $\mathrm{ICH}$ & - & - & 11 & - & 0.97 - non-Asian & - \\
\hline \multirow[t]{4}{*}{ Zulkifly et. al (27) } & Stroke / TIA & 4.5 & 6.5 & 4.9 & - & - & - \\
\hline & Bleeding & 4.5 & 9.8 & 5.9 & - & - & - \\
\hline & CVS hospitalization & 21.3 & 25.6 & 32.3 & - & - & - \\
\hline & Death & 2.5 & 1.2 & 2.0 & - & - & - \\
\hline Graham et al. (49) & Bleeding & - & - & - & - & - & 1.3 \\
\hline \multirow[t]{2}{*}{ Lip et al. (38) } & Bleeding & - & - & - & - & - & $1.3-7.4$ \\
\hline & $\mathrm{ICH}$ & - & - & - & - & - & $0.3-2.5$ \\
\hline \multirow[t]{2}{*}{ Guo et al. (10) } & Bleeding & - & - & - & - & - & $1-1.5$ \\
\hline & $\mathrm{ICH}$ & - & - & - & - & - & 0.4 \\
\hline \multirow[t]{2}{*}{ Guo et al. (50) } & Major bleeding & - & - & - & - & - & 1.14 \\
\hline & Major bleeding $+\mathrm{ICH}$ & - & - & - & - & - & 0.52 \\
\hline
\end{tabular}

ICH, intracranial haemorrhage; TIA, transient ischemic attack; IS, ischemic stroke.

4.5\%) and Asian (4.9 and 5.9\%) population, respectively. A meta-analysis of 10 studies comparing the prevalence of AF among African Americans to Whites in the United States concluded that being African American was associated with a "protective effect" from AF [OR 0.51 (95\% CI 0.44-0.59); $p<0.001]$. Despite that, African Americans have twice the risk of first ever stroke compared to Whites and this might be due to higher risk factor burden of stroke, for example, hypertension (51).

Besides stroke and TIA, patients on warfarin therapy are also at risk of getting intracranial haemorrhage $(\mathrm{ICH})$ with double the risk in Asians relative to the Whites (43). Clinical trials $(52,53)$ have shown low TTR among Asians compared to nonAsians; however, the rates of major bleeding were significantly higher in Asian patients $(53,54)$. The reasons behind this are not completely understood but one small Chinese study $(n=290)$ (54) reported the presence of cerebral microbleeds (CMBs) which was associated with numerically higher incidence of ICH among their AF patients on warfarin therapy compared to those without CMBs (3.6 vs. $0.7 \%, p=0.129$ ).

\section{STRENGTHS AND LIMITATIONS OF THE REVIEW}

This is the first review summarising the prevalence, quality of anticoagulation control (TTR), and adverse clinical outcome among AF patients on warfarin therapy within different ethnic groups. Clinicians could understand the underlying factors that influence the treatment outcome among these ethnic groups. Rational prescribing of NOAC and warfarin could be improved by having the snapshot view of AF disease burden and their clinical outcomes in terms of stroke prevention. Nevertheless, the findings derived from this review are limited with caveats such as more than half of the included studies are retrospective in nature, the number of patients included were small and not represented in some parts of the world such as the Middle East and areas other than mainland China and Western Europe.

\section{CONCLUSION}

In conclusion, this review represents the differences in the prevalence of AF, anticoagulation control with warfarin therapy and adverse clinical outcomes among different ethnic groups across the globe. Findings suggest higher prevalence of AF but better anticoagulation control among the Whites as compared to other ethnicities. Unfortunately, non-whites had higher risk of strokes and bleeding outcomes while on warfarin therapy. Addressing disparities in prevention and healthcare resource allocation will likely improve AF-related outcomes in minorities.

\section{AUTHOR CONTRIBUTIONS}

HZ: conceptualization and supervision. NZ, IA, and HZ: methodology, formal analysis, investigation, data curation, writing-original draft preparation, and project administration. 
NZ, IA, LM, and HZ: software and validation. LM, HPG, and HZ: resources, writing-review and editing, and funding acquisition.

\section{REFERENCES}

1. Lip GYH, Tello-Montoliu A. Management of atrial fibrillation. Heart. (2006) 92:1177-82. doi: 10.1136/hrt.2005.071555

2. Hindricks G, Potpara T, Dagres N, Bax JJ, Boriani G, Dan GA, et al. 2020 ESC guidelines for the diagnosis and management of atrial fibrillation developed in collaboration with the European Association for Cardio-Thoracic Surgery (EACTS). Eur Heart J. (2021) 42:373-498. doi: 10.1093/eurheartj/ ehaa612

3. Pistoia F, Sacco S, Tiseo C, Degan D, Ornello R, Carolei A. The epidemiology of atrial fibrillation and stroke. Cardiol Clin. (2016) 34:255-68. doi: 10.1016/j.ccl.2015.12.002

4. Pastori D, Pignatelli P, Cribari F, Carnevale R, Saliola M, Violi F, et al. Time to therapeutic Range (TtTR), anticoagulation control, and cardiovascular events in vitamin $\mathrm{K}$ antagonists-naive patients with atrial fibrillation. Am Heart J. (2018) 200:32-6. doi: 10.1016/j.ahj.2018.03.004

5. Melamed OC, Horowitz G, Elhayany A, Vinker S. Quality of anticoagulation control among patients with atrial fibrillation. Am J Manag Care. (2011) 17:232-7. Available online at: https://www.ajmc.com/view/ajmc_11mar melamed_232to237 (accessed May 31, 2021).

6. Fitzmaurice DA, Blann AD, Lip GYH. ABC of antithrombotic therapy: bleeding risks of antithrombotic therapy. BMJ. (2002) 325:828-31. doi: 10.1136/bmj. 325.7368 .828

7. Apostolakis S, Sullivan RM, Olshansky B, Lip GYH. Factors affecting quality of anticoagulation control among patients with atrial fibrillation on warfarin. Chest. (2013) 144:1555-63. doi: 10.1378/chest.13-0054

8. Rahmadina A, Gofir A, Nugroho AE. The role of anticoagulation control on the mortality rate in warfarin treated ischemic stroke patients with atrial fibrillation. IJPCR. (2015) 7:311-5. doi: 10.25258/ijpcr.v7i4.15

9. Bernaitis N, Ching CK, Chen L, Hon JS, Teo SC, Badrick T, et al. A high HASBLED score identifies poor warfarin control in patients treated for non-valvular atrial fibrillation in Australia and Singapore. Basic Clin Pharmacol Toxicol. (2017) 121:499-504. doi: 10.1111/bcpt. 12836

10. Guo Y, Wang H, Tian Y, Wang Y, Lip GYH. Time trends of aspirin and warfarin use on stroke and bleeding events in Chinese patients with new-onset atrial fibrillation. Chest. (2015) 148:62-72. doi: 10.1378/chest.14-2018

11. Heckbert SR, Austin TR, Jensen PN, Chen LY, Post WS, Floyd JS, et al. Differences by race_ethnicity in the prevalence of clinically detected and monitor-detected atrial fibrillation. Circ Arrhythm Electrophysiol. (2020) 13:e007698. doi: 10.1161/CIRCEP.119.007698

12. Mathur R, Pollara E, Hull S, Schofield P, Ashworth M, Robson J. Ethnicity and stroke risk in patients with atrial fibrillation. Heart. (2013) 99:1087-92. doi: 10.1136/heartjnl-2013-303767

13. Gillott RG, Willan K, Kain K, Sivananthan UM, Tayebjee MH. South Asian ethnicity is associated with a lower prevalence of atrial fibrillation despite greater prevalence of established risk factors: a population-based study in Bradford Metropolitan District. Europace. (2017) 19:356-63. doi: 10.1093/europace/euw010

14. Magnani JW, Norby FL, Agarwal SK, Soliman EZ, Chen LY, Loehr LR, et al. Racial differences in atrial fibrillation-related cardiovascular disease and mortality the Atherosclerosis Risk in Communities (ARIC) study. JAMA Cardiology. (2016) 1:433-41. doi: 10.1001/jamacardio.2016.1025

15. Lim CW, Kasim S, Ismail JR, Chua NYC, Najme Khir R, Zainal Abidin HA, et al. Prevalence of atrial fibrillation in the Malaysian communities. Heart Asia. (2016) 8:62-6. doi: 10.1136/heartasia-2016-010775

16. Kamel H, Kleindorfer DO, Bhave PD, Cushman M, Levitan EB, Howard G, et al. Rates of atrial fibrillation in black versus white patients with pacemakers. J Am Heart Assoc. (2016) 5:e002492. doi: 10.1161/JAHA.115.002492

17. Jensen PN, Thacker EL, Dublin S, Psaty BM, Heckbert SR. Racial differences in the incidence of and risk factors for atrial fibrillation in older adults: the cardiovascular health
All authors have read and agreed to the published version of the manuscript. study. J Am Geriatr Soc. (2013) 61:276-80. doi: 10.1111/jgs. 12085

18. Lau CP, Gbadebo TD, Connolly SJ, van Gelder IC, Capucci A, Gold MR, et al. Ethnic differences in atrial fibrillation identified using implanted cardiac devices. J Cardiovasc Electrophysiol. (2013) 24:381-7. doi: 10.1111/jce.12066

19. Lahiri MK, Fang K, Lamerato L, Khan AM, Schuger CD. Effect of race on the frequency of postoperative atrial fibrillation following coronary artery bypass grafting. Am J Cardiol. (2011) 107:383-6. doi: 10.1016/j.amjcard.2010.09.032

20. Winkelmayer WC, Patrick AR, Liu J, Brookhart MA, Setoguchi S. The increasing prevalence of atrial fibrillation among hemodialysis patients. J Am Soc Nephrol. (2011) 22:349-57. doi: 10.1681/ASN.2010050459

21. Marcus GM, Alonso A, Peralta CA, Lettre G, Vittinghoff E, Lubitz SA, et al. European ancestry as a risk factor for atrial fibrillation in African Americans. Circulation. (2010) 122:2009-15. doi: 10.1161/CIRCULATIONAHA.110.958306

22. Shen AYJ, Contreras R, Sobnosky S, Shah AI, Ichiuji AM, Jorgensen MB, et al. Racial/ethnic differences in the prevalence of atrial fibrillation among older adults - a cross-sectional study. J Natl Med Assoc. (2010) 102:906-14. doi: 10.1016/S0027-9684(15)30709-4

23. Go AS, Hylek EM, Phillips KA, Chang Y, Henault LE, Selby JV, et al. Prevalence of diagnosed atrial fibrillation in adults: national implications for rhythm management and stroke prevention: the anticoagulation and risk factors in atrial fibrillation (ATRIA) study. J Am Med Assoc. (2001) 285:2370-5. doi: 10.1001/jama.285.18.2370

24. Borzecki AM, Bridgers DK, Liebschutz JM, Kader B, Kazis LE, Berlowitz DR. Racial differences in the prevalence of atrial fibrillation among males. J Natl Med Assoc. (2008) 100:237-46. doi: 10.1016/S0027-9684(15)31212-8

25. Shavadia J, Yonga G, Mwanzi S, Jinah A, Moriasi A, Otieno H. Clinical characteristics and outcomes of atrial fibrillation and flutter at the Aga Khan University Hospital, Nairobi. Cardiovasc J Afr. (2013) 24:6-9. doi: 10.5830/CVJA-2012-064

26. Caldeira D, Cruz I, Morgado G, Stuart B, Gomes C, Martins C, et al. Evaluation of time in therapeutic range in anticoagulated patients: a singlecenter, retrospective, observational study. BMC Res Notes. (2014) 7:1-5. doi: 10.1186/1756-0500-7-891

27. Zulkifly H, Cheli P, Lutchman I, Bai Y, Lip GYH, Lane DA. Anticoagulation control in different ethnic groups receiving vitamin $\mathrm{K}$ antagonist therapy for stroke prevention in atrial fibrillation. Thromb. Res. (2020) 192:12-20. doi: 10.1016/j.thromres.2020.04.001

28. Nguyen MT, Gallagher C, Pitman BM, Emami M, Kadhim K, Hendriks JM, et al. Quality of warfarin anticoagulation in indigenous and non-indigenous Australians with atrial fibrillation. Heart Lung Circ. (2020) 29:1122-8. doi: 10.1016/j.hlc.2019.11.006

29. Li Y, Yu J, Kuang Y, Wu C, Yang L, Fang Q, et al. Quality of oral anticoagulation control in Chinese patients with non-valvular atrial fibrillation: a prospective controlled study. Curr Med Res Opin. (2020) 36:1433-9. doi: 10.1080/03007995.2020.1796611

30. Urbonas G, Valius L, Šakalyte G, Petniunas K, Petniuniene I. The quality of anticoagulation therapy among warfarin-treated patients with atrial fibrillation in a primary health care setting. Medicina. (2019) 55:15. doi: $10.3390 /$ medicina55010015

31. Roldán Rabadán I, Esteve-Pastor MA, Anguita-Sánchez M, Muñiz J, Camacho Siles J, Quesada MA, et al. Relation of quality of anticoagulation control with different management systems among patients with atrial fibrillation: data from FANTASIIA registry. Eur J Clin Invest. (2018) 48:e12910. doi: 10.1111/eci.12910

32. Mohammed S, Aljundi AHS, Kasem M, Alhashemi M, El-Menyar A. Anticoagulation control among patients with nonvalvular atrial fibrillation: a single tertiary cardiac center experience. J Adv Pharm Technol Res. (2017) 8:14-8. doi: 10.4103/2231-4040.197370

33. Bernaitis N, Ching CK, Chen L, Hon JS, Teo SC, Davey AK, et al. The sex, age, medical history, treatment, tobacco use, race risk (SAMe TT2R2) score 
predicts warfarin control in a Singaporean population. J Stroke Cerebrovasc Dis. (2017) 26:64-9. doi: 10.1016/j.jstrokecerebrovasdis.2016.08.030

34. Abbasinazari M, Farsad BF, Dabagh A, Bakshandeh H. Evaluation of Time in Therapeutic Range (TTR) in patients with non-valvular atrial fibrillation receiving treatment with warfarin in Tehran, Iran: a cross-sectional study. $J$ Clin Diagn Res. (2016) 10:FC04-6. doi: 10.7860/JCDR/2016/21955.8457

35. Yap SH, Ng YP, Roslan A, Kolanthaivelu J, Koh KW, P'ng HS, et al. A comparison of dabigatran and warfarin for stroke prevention in elderly Asian population with nonvalvular atrial fibrillation: an audit of current practice in Malaysia. Med J Malaysia. (2017) 72:360-4.

36. Chan PH, Hai JJ, Chan EW, Li WH, Tse HF, Wong ICK, et al. Use of the SAMeTT2R2 score to predict good anticoagulation control with warfarin in Chinese patients with atrial fibrillation: relationship to ischemic stroke incidence. PLoS ONE. (2016) 11:e0150674. doi: 10.1371/journal.pone.0150674

37. Golwala H, Jackson LR, Simon DJN, Piccini JP, Gersh B, Go AS, et al. Racial/ethnic differences in atrial fibrillation symptoms, treatment patterns, and outcomes: insights from outcomes registry for better informed treatment for atrial fibrillation registry. Am Heart J. (2016) 174:29-36. doi: 10.1016/j.ahj.2015.10.028

38. Lip GYH, Waldo AL, Ip J, Martin DT, Bersohn MM, Choucair WK, et al. Determinants of time in therapeutic range in patients receiving oral anticoagulants (A Substudy of IMPACT). Am J Cardiol. (2016) 118:1680-4. doi: 10.1016/j.amjcard.2016.08.047

39. Yong C, Azarbal F, Abnousi F, Heidenreich PA, Schmitt S, Fan J, et al. Racial differences in quality of anticoagulation therapy for atrial fibrillation (from the TREAT-AF Study). Am J Cardiol. (2016) 117:61-8. doi: 10.1016/j.amjcard.2015.09.047

40. Barta AL, Nutescu EA, Thompson PA, Bussey HI, Gulseth MP. Relationship between time spent at extreme international normalized ratios and time in therapeutic range with bleeding and thrombosis in warfarin-treated patients. Am J Health Syst Pharm. (2015) 72:1188-94. doi: 10.2146/ajhp140752

41. MacEdo AF, Bell J, McCarron C, Conroy R, Richardson J, Scowcroft A, et al. Determinants of oral anticoagulation control in new warfarin patients: analysis using data from Clinical Practice Research Datalink. Thromb Res. (2015) 136:250-60. doi: 10.1016/j.thromres.2015. 06.007

42. Singer DE, Hellkamp AS, Piccini JP, Mahaffey KW, Lokhnygina Y, Pan G, et al. Impact of global geographic region on time in therapeutic range on warfarin anticoagulant therapy: data from the ROCKET AF clinical trial. J Am Heart Assoc. (2013) 2:67. doi: 10.1161/JAHA.112.000067

43. Birman-Deych E, Radford MJ, Nilasena DS, Gage BF. Use and effectiveness of warfarin in medicare beneficiaries with atrial fibrillation. Stroke. (2006) 37:1070-4. doi: 10.1161/01.STR.0000208294.46968.a4

44. Chiang CE, Wang KL, Lin SJ. Asian strategy for stroke prevention in atrial fibrillation. Europace. (2015) 17 (suppl. 2). doi: 10.1093/europace/euv231

45. AL-Eitan LN, Almasri AY, Khasawneh RH. Effects of CYP2C9 and VKORC1 polymorphisms on warfarin sensitivity and responsiveness during the stabilization phase of therapy. Saudi Pharm J. (2019) 27:484-90. doi: 10.1016/j.jsps.2019.01.011

46. Kabra R, Girotra S, Vaughan Sarrazin M. Refining stroke prediction in atrial fibrillation patients by addition of African-American ethnicity to CHA2DS2-VASc score. J Am Coll Cardiol. (2016) 68:461-70. doi: $10.1016 /$ j.jacc.2016.05.044
47. Shen AYJ, Yao JF, Brar SS, Jorgensen MB, Chen W. Racial/ethnic differences in the risk of intracranial hemorrhage among patients with atrial fibrillation. $J$ Am Coll Cardiol. (2007) 50:309-15. doi: 10.1016/j.jacc.2007.01.098

48. Wang KL, Lip GYH, Lin SJ, Chiang CE. Non-vitamin $K$ antagonist oral anticoagulants for stroke prevention in Asian patients with nonvalvular atrial fibrillation: meta-analysis. Stroke. (2015) 46:2555-61. doi: 10.1161/STROKEAHA.115.009947

49. Graham DJ, Baro E, Zhang R, Liao J, Wernecke M. Comparative stroke, bleeding, and mortality risks in older medicare patients treated with oral anticoagulants for non-valvular atrial fibrillation. Am J Med. (2019) 132:596604.e11. doi: 10.1016/j.amjmed.2018.12.023

50. Guo YT, Zhang Y, Shi XM, Shan ZL, Wang CJ, Wang YT, et al. Assessing bleeding risk in 4824 Asian patients with atrial fibrillation: the Beijing PLA hospital atrial fibrillation project. Sci Rep. (2016) 6:31755. doi: 10.1038/srep31755

51. Hernandez MB, Asher CR, Hernandez AV, Novaro GM. African American race and prevalence of atrial fibrillation: a meta-analysis. Cardiol Res Pract. (2012) 2012:275624. doi: 10.1155/2012/275624

52. Oldgren J, Healey JS, Ezekowitz M, Commerford P, Avezum A, Pais $\mathrm{P}$, et al. Variations in cause and management of atrial fibrillation in a prospective registry of 15,400 emergency department patients in 46 countries. Circulation. (2014) 129:1568-76. doi: 10.1161/CIRCULATIONAHA.113.0 05451

53. Chiang CE, Wang KL, Lip GYH. Stroke prevention in atrial fibrillation: an Asian perspective. Thromb Haemost. (2014) 111:789-97. doi: 10.1160/TH13-11-0948

54. Yasaka M, Lip GYH. Impact of non-vitamin K antagonist oral anticoagulants on intracranial bleeding in Asian patients with non-valvular atrial fibrillation. Circ J. (2014) 78:2367-72. doi: 10.1253/circj.CJ-14-0720

55. Lip GYH, Andreotti F, Fauchier L, Huber K, Hylek E, Knight E, et al. Bleeding risk assessment and management in atrial fibrillation patients: a position document from the European heart rhythm association, endorsed by the European society of cardiology working group on thrombosis. Europace. (2011) 13:723-46. doi: 10.1093/europace/eur126

Conflict of Interest: The authors declare that the research was conducted in the absence of any commercial or financial relationships that could be construed as a potential conflict of interest.

Publisher's Note: All claims expressed in this article are solely those of the authors and do not necessarily represent those of their affiliated organizations, or those of the publisher, the editors and the reviewers. Any product that may be evaluated in this article, or claim that may be made by its manufacturer, is not guaranteed or endorsed by the publisher.

Copyright @ 2021 Zawawi, Abdul Halim Zaki, Ming, Goh and Zulkifly. This is an open-access article distributed under the terms of the Creative Commons Attribution License (CC BY). The use, distribution or reproduction in other forums is permitted, provided the original author(s) and the copyright owner(s) are credited and that the original publication in this journal is cited, in accordance with accepted academic practice. No use, distribution or reproduction is permitted which does not comply with these terms. 